\title{
位相制御と筋緊張制御の有機的整合が可能な脚歩行ロボットの開発 Development of a Legged Robot That Enables Well-balanced Coupling between Phasic and Tonic Control
}

\author{
$\bigcirc$ 糸澤 祐太 (東北大) Skarka Martin（東北大） \\ 佐藤 貴英（東北大） 加納 剛史（東北大） \\ 正 石黒 章夫（東北大 / JST CREST）
}

\author{
Yuta ITOZAWA, Tohoku University, itozawa@cmplx.ecei.tohoku.ac.jp \\ Martin SKARKA, Tohoku University \\ Takahide SATO, Tohoku University \\ Takeshi KANO, Tohoku University \\ Akio ISHIGURO, Tohoku University / JST CREST
}

\begin{abstract}
A systematic way of designing autonomous decentralized control system is still missing, despite its appealing concept. In order to alleviate this, we have so far focused on serpentine locomotion, and have proposed a design scheme of interaction between the control and mechanical systems in which both the phasic and tonic control are taken into account. In this paper, we aim to verify the validity and universality of this design scheme by applying it to legged locomotion. As a first step, we develop a cart-pulling biped robot which has a simple mechanical structure. The preliminary experimental results show that phasic and tonic control are well-coordinated.
\end{abstract}

Key Words: Autonomous decentralized control, Discrepancy function, Phasic/tonic control, Legged locomotion

\section{1.はじめに}

生物は非構造的で予測不能的に変動する環境下であっても,リ アルタイムかつ合目的的に振る舞う適応的な知を有している。こ のような知を発現し，あたかも生物のごとく柔らかくしなやかに 動き回ることのできるロボットを創り出すためには, ロボットの 身体に生物同様の大きな自由度を持たせ, かつそれらを巧みに制 御することが必要となる。そこで, 大自由度系を扱う制御方策と して着目されているのが自律分散制御である。自律分散制御と は, 単純な知覚・判断・行動出力の機能を持つ要素 (自律個) が 多数集まり相互作用することで，大域的に有用な機能を創発させ る制御方策である。このような特性ゆえに，高い適応性を有する 大自由度ロボットの設計に際して強力なツールとなることが期待 されている。

しかしながら，自律分散制御に関する体系的な設計論はいま だ存在していないのが現状である，なぜならば，協働的振る舞い を発現するための「個（自律個）」と「全体」をつなぐロジック が依然として欠如しているためである.この問題を解決するため には，(1) 自律個のダイナミクス，(2) 自律個間の相互作用様式, そして (3) 制御系（自律個集団）と機構系 (身体) の連関様式, に対して明確な設計指針を与えることが必要である. 上記 (1) と (2)に関しては, 結合振動子系を用いた運動制御などの既存研究 に㧍いて議論されているものの [1]-[5]，(3) に関しては事例ごと にアドホックかつテーラーメイドに設計されているのが現状であ る，この事実を踏まえ，特に(3) に関する体系的な考察は喫緊の 課題であるといえる。

そこで筆者らは，特に上記 (3) に焦点を当て研究を行ってき た. 具体的には，純粋に自律分散制御がなされている真性粘菌変 形体のアメーバ様ロコモーションに着目することで, 疊峿関数 (discrepancy function) に基づく局所センサフィードバック則の 設計スキームを得た $[6][7]$. これは, 制御系・機構系・環境間に 生じる粿嘼を身体の局所情報に基づいて検出し，それを制御系を 構成する振動子の位相にフィードバックすることで，制御系と機 構系の連関を図るというものであった。この制御則は, さらに高 等な生物であるへビの這行用ロコモーションにも適用され，その
妥当性が検証されてきた $[8]$.

しかしながら，実際の生物が示すような高い適応能力を実現 するには，このような位相のみに着目した制御則では不十分で ある。なぜならば，生物は身体各部の位相関係のみならず，筋緊 張がもたらす作用力やスティフネスの空間分布を環境に応じて 巧みに変化させているからである。最近，筆者らは位相制御と筋 緊張制御の双方を考慮した局所センサフィードバック則を提唱し た [9].そして，この制御則をへビの這行様ロコモーションに適 用してシミュレーション実験を行い, 優れた環境適応性が実現で きることを示してきた。しかしながら，この制御則の普遍性を示 すには，ヘビよりもさらに高等なロコモーション様式において， その妥当性を検証する必要がある。

そこで本研究では脚歩行に着目する.本研究は初動段階にある ため, 問題の簡単化のために荷車を毫引する二脚ロボットの自律 分散制御を採り上げる。そして, 設計した制御則を実装した実機 を開発し，位相制御と筋緊張制御が適切に行われることを実験的 に検証する。

\section{2. モデル}

\section{1 機構系}

本研究で用いるロボットの模式図を図 1 に示す。ロボットは 二本の脚と荷車から構成されており，各脚には股関節と膝関節が 存在し, それぞれピッチ方向にのみ自由度を有している。 そし て，各関節は拮抗的に取り付けられた可変弾性要素（Real-time Tunable Spring : RTS) によって駆動される. 可変弾性要素と は，自然長を実時間かつ動的に改変可能なバネであり，このよう な特性ゆえに，能動性と受動性の双方を兼ね備えた機械要素と いえる. $i$ 番目の関節に取り付けられた可変弾性要素にかかる力 $F_{i}^{R T S}$ は，次のように記述される：

$$
F_{i}^{R T S}=\frac{\alpha}{l_{i}^{R T S}} \operatorname{Max}\left[0, l_{i}-l_{i}^{R T S}\right] .
$$

ここで, $l_{i}, l_{i}^{R T S}$ は可変弾性要素の㬰際の長さ，ならびに自然 長である. $\alpha / l_{i}^{R T S}$ は可变弾性要素のバネ定数であり, 筋緊張度 


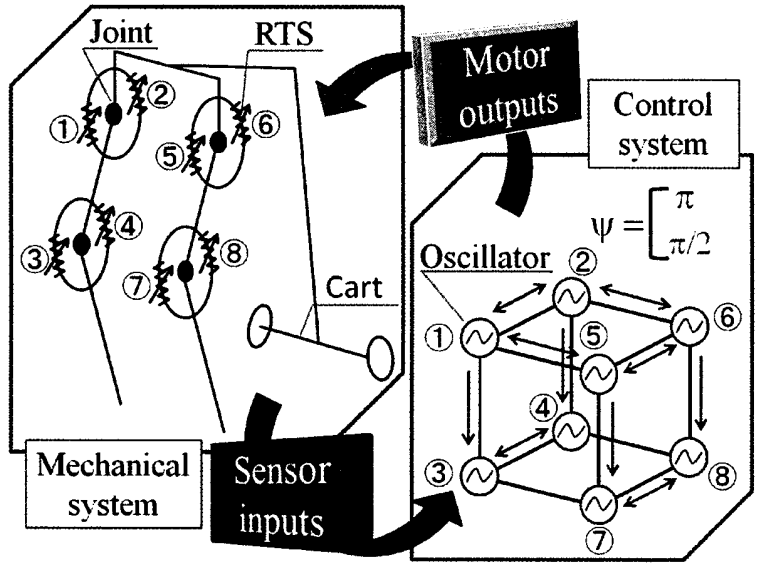

Fig. 1 Schematic illustration of control and mechanical systems.

を特徴づけている. 自然長 $l_{i}^{R T S}$ が短くなるにつれ, 筋緊張が高 まることに注意されたい. 各関節の両側の可変弾性要素にかかる 力は拮抗的に働くため, 差動トルクによって関節を曲げることが できる.これにより脚歩行運動を実現することができる.

\section{2 制御系}

本節では，上記機構系を自律分散的に制御する設計論を示す. 図 1 に示すように, 制御系の自律個の素過程として各可变弾性 要素ごとに振動子を導入し, 結合振動子系を構成する。ここで, 各可変弾性要素と振動子との対応関係は図中の番号によって与え られるものとする．本モデルでは拮抗筋の位相関係だけでなく筋 緊張の空間分布のダイナミクスにも着目するため, $i$ 番目の可変 弾性要素に対応寸る振動子を位相 $\phi_{i}$ と振幅 $R_{i}$ の 2 変数で記述 する．位相 $\phi_{i}$ の時間発展は以下の式 (2) で記述される：

$$
\frac{d \phi_{i}}{d t}=\omega+\sum_{j} \varepsilon_{i j} \sin \left(\phi_{j}-\phi_{i}-\psi_{i j}\right)-\varepsilon_{1} \frac{\partial I_{i}}{\partial \phi_{i}} .
$$

ここで, $\omega$ は振動子の固有角振動数である. 右辺第 2 項は, 振 動子間の相互作用項であり, 隣接する振動子間の位相差が $\psi_{i j} に$ 引き込まれるように設定されている. $\psi_{i j}$ の具体的な值は図 1 に 示す.ここで, $\varepsilon_{i j}$ は振動子間の結合強度を表している. 右辺第 3 項は機構系からの局所センサフィードバックを表している. $I_{i}$

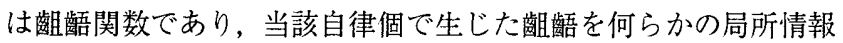
に基づいて検出する関数である. 本モデルでは, 環境との相互 作用の結果決定される実際の長さ $l_{i}$ と, 制御系からの指令值に よって決定される可変弾性要素の自然長 $l_{i}^{R T S}$ の差を用いて喟嘼 関数 $I_{i}$ を式 (3)のように設計した：

$$
I_{i}=\left(l_{i}-l_{i}^{R T S}\right)^{2} .
$$

この位相への局所センサフィードバックは, 従来研究 [6][7][8] と 同様に, 自律個の位相の修正によって臈龉を軽減することで, 制 御系と機構系の有機的整合を図っている.

一方，振幅 $R_{i}$ の時間発展は次のように記述される：

$$
\frac{d R_{i}}{d t}=\varepsilon_{2}\left(\alpha \sqrt{I_{i}}-R_{i}\right) .
$$

ここで, $\varepsilon_{2}$ と $\alpha$ は正の定数である. (4) 式は, 苴龉の変化に追 随して振動子の振幅が変化することを意味している. 可変弾性要 素の自然長 $l_{i}^{R T S}$ は次式のように設定する：

$$
l_{i}^{R T S}=a \cos \phi_{i}+b+c \mathrm{e}^{-\beta R_{i}} .
$$

ここで, $a, b, c, \beta$ は正の定数である. 右辺第 1 項は, 位相の周 期的変動に対応した拮抗筋の収縮. 弛緩の繰返しを表している。 右辺第 2 項はバイアス項である. 右辺第 3 項は, 振幅 $R_{i}$ が大き くなると可変弾性要素の自然長が短くなることを意味している. したがって, 䕬梧が生じると遅れて振幅 $R_{i}$ が大きくなり, それ により自然長 $l_{i}^{R T S}$ が短くなることで可変弾性要素のバネ定数が 増加するという, 笳緊張へのフィードバック機構が存在している.

\section{3. 実機}

本研究で用いる実機の全体像を図 2 に示す。本ロボットは脚部 と荷車部から構成され, 全長は約 $0.64[\mathrm{~m}]$, 全幅約 $0.27[\mathrm{~m}]$, 全 高約 $0.45[\mathrm{~m}]$, 全質量約 $3.1[\mathrm{~kg}]$ である. 脚部は二本の脚から構 成されており, 各脚には股関節と膝関節が存在している. 関節動 作はピッチ方向のみの自由度を有しており, 各関節には拮抗的に 配置された可変弾性要素が実装されている. 可变弾性要素の部 分を図 3 に示す. 可変弾性要素は, シリコンゴムとサーボモー 夕で構成されており, シリコンゴムをサーボモータで巻き上げ ることで弾性体の自然長を実時間かつ動的に変えることができ る. 脚部には, 関節角度を検出することで可变弾性要素の実際の 長さ $l_{i}$ を算出するための可変抵抗, それぞれの可変弾性要素に 対応する振動子を実装したマイクロコンピュータ (Atmel AVR Atmega128p），ロボットの内部デー夕取得用の無線通信用回路 基板, 電源バッテリーが内蔵されている. 脚式ロコモーションは 各関節に実装された可变弾性要素の自然長を周期的に変化させ ることで実現できる。

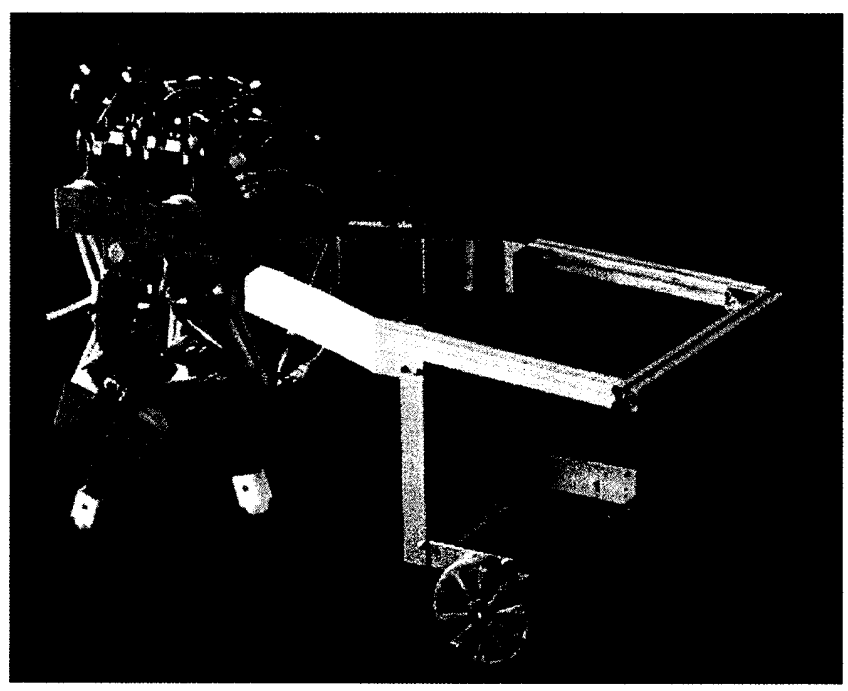

Fig. 2 Overview of cart-pulling biped robot. 


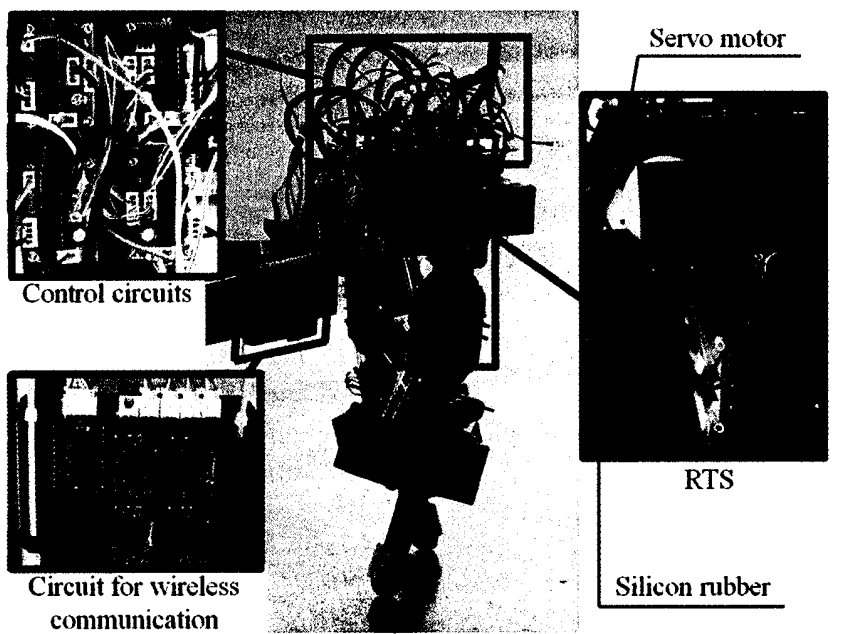

Fig. 3 Detailed structure of the cart-pulling biped robot.

\section{4. 予備実験}

本節では，開発した実機を用いた予備実験の結果を報告する。 具体的には，渞䓊が生じたときに適切に位相制御と筋緊張制御 が行われているかを確認した，実験方法は，図4で示すように， 無負荷状態で周期運動する一方の股関節に前後方向から手で外力 を与え動きを一定時間止めるというものである．結果を図 5 に 示す.グラフは, 上からそれぞれ当該脚の撂吿 $I_{i}$, 振幅 $R_{i}$, 位 相 $\sin \phi_{\mathbf{i}}$ を表しており, 網掛け部分で前後から外力を加えた，図 からわかるように外力が加わった時に疊嘼 $I_{i}$, 振幅 $R_{i}$ が大きく なり筋緊張制御が行われていることがわかる. 一方位相は, 本来 の周期よりも遅れていることがわかる，このことから，位相制御 も適切に行われていることが確認された。

\section{5. まとめと今後の展望}

本稿では，生物の示す多様なロコモーション様式に通底する 制御のからくりを解明することを目指し, 大自由度系の制御方策 として自律分散制御に着目した. 自律分散制御の設計論構築には 制御系と機構系の連関様式に関する体系的な考察が喫緊の課題 である。そこで, 本研究では位相制御と筋緊張制御が連関した制 御則を脚歩行に適用し, その初動段階として荷車を牽引する二脚 ロボットの実機を開発した. 予備実験の結果, 制御系と機構系の (i)

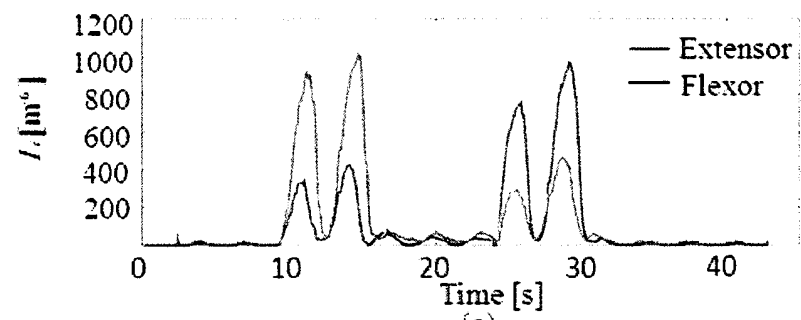

(a)

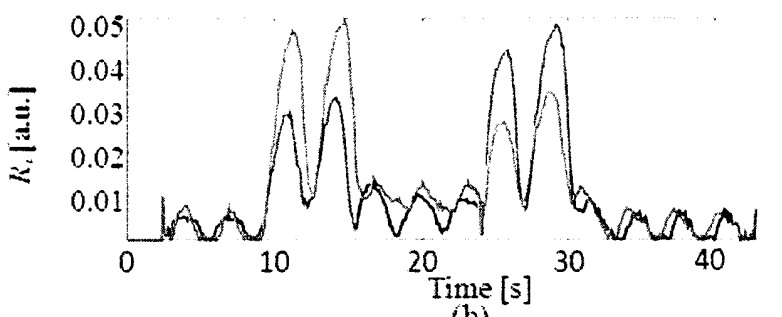

(b)

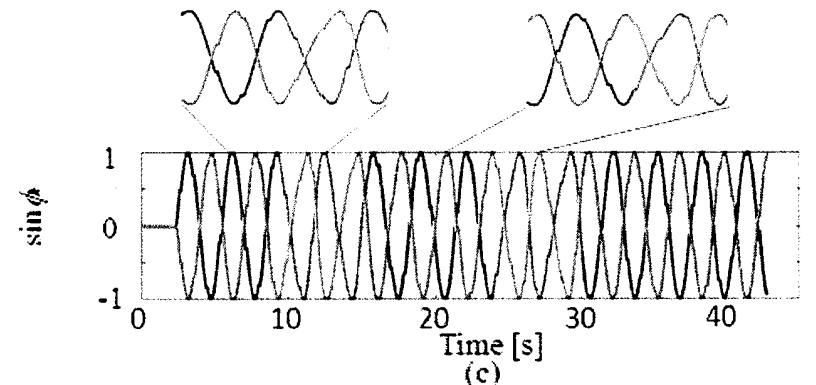

(c)

Fig. 5 Time evolutions of (a) discrepancy $I_{i}$, (b) amplitude $R_{i}$, and (c) phase $\phi_{i}$. Shaded regions denote the period when an external force is applied (i) forward and (ii)backward, respectively.

間のずれ（䕬齬 $I_{i}$ ）が生じると振幅 $R_{i}$ が大きくなるとともに位 相速度が遅くなり，このことから筋緊張制御と位相制御が適切に 行われていることが確認された。開発した実機を用いた不整地・ 上り坂・下り坂においての歩行実験などの結果は発表当日に報告 する。

\section{文 献}

[1] Kimura, H., Fukuoka, Y. and Nakamura, H., "Biologically inspired adaptive dynamic walking of the quadruped on irregular terrain", in Proc. of ISRR99, pp.271-278, 1999.

[2] Kimura, H., Akiyama, S. and Sakurama, K., "Realization of Dynamic Walking and Running of the Quadruped Using Neural Oscillator", Autonomous Robots, vol.7, no.3, pp.247-258, 1999.

[3] Taga, G., Yamaguchi, Y. and Shimizu, H., "Self-organized control of bipedal locomotion by neural oscillators", Biol. Cybern., vol.65, pp.147-159, 1991.

[4] Taga, G., "Emergence of bipedal locomotion through entrainment among the neuro-musculo-skeletal system and the environment", Physica D: Nonlinear Phenomena, vol.75, no.1-3, pp.190-208, 1994.
Fig. 4 Preliminary experiment. An external force is applied (i) forward and (ii) backward on the hip joint, respectively. 
[5] Taga, G., "A model of the neuro-musculo-skeletal system for human locomotion - II. Real-time adaptability under various constraints", Biol. Cybern., vol.73, pp.97-111, 1995.

[6] Kobayashi, R., Tero, A. and Nakagaki, T., "Mathmatical model for rhythmic protoplasimic movement in the true slime mold", L.Math.Biol., vol.53, pp.273-286, 2006.

[7] Umedachi, T., Takeda, K., Nakagaki, T., Kobayashi, R., and Ishiguro, A. "Fully Decentralized Control of a Soft-bodied Robot Inspired by True Slime Mold", Biol. Cybern., vol. 102, pp. 261-269, 2010.

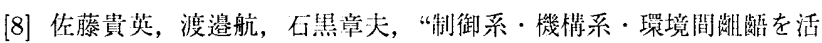
用したヘビ型ロボットの自律分散制御”，第 27 回日本ロボット学 会学術部演会学会于稿集 CD-ROM, RSJ2009AC1M2-04, 2009.

[9] 加納剧史，佐藤貴英，小林亮，不黑管夫，“位相制御と筋緊张制御の 有機的整合を可能とする自律分敞制御則〜へビ型ロボットを用い た事例研究〜”，第 22 回 自律分瓶システム・シンポジウム资料， pp159-164, 2010. 